\title{
Memetics: A Practical Translation Theory in Business Environment-Take Safeguard as an Example
}

\author{
Lu Yuan*, Xiangting He, Qianying Quan \\ Leshan Normal University, China
}

\begin{abstract}
Brand name translation plays an important role in foreign trade. From the perspective of memetics, this paper analyzes the sales and popularity of Luxury and Safeguard in China, discusses the persistence of Memetics and the crosslanguage transmission of brand memes, which is helpful for translators to translate authentic brand names, so as to speed up the reproduction and dissemination of brand names, increase the probability of becoming a strong meme, and enhance the international popularity of brands.
\end{abstract}

Key words: Brand name translation; Memetics; Meme; Translation strategy; Longevity

Publication date: April, 2021; Publication online: 30 April, 2021

*Corresponding author: Lu Yuan, 13355420796@163.com

\section{Introduction}

As a special linguistic phenomenon, the brand name, an essential component of advertisement, has aroused interest of linguists as well as that of economists. The quality of brand translation has a great influence on the acceptance of products in the target market. With the implementation of the Belt and Road Initiative strategy and the increasing circulation of import and export commodities, trademark translation is becoming more and more important. Nowadays, Memetics is widely used in trademark translation.

Memetics is a newly developed theory aiming to explicate the evolutionary mechanisms of culture from the perspective of Darwinism. It refers to the ideas or ideas that are imitated and spread among people in the field of culture and passed down from generation to generation. Language itself is a meme, and memes are also contained in language. Any word, sentence or text can be memes as long as it is copied or spread through imitation ${ }^{[1]}$. In addition, Memetics has three characteristics. Dawkins (1993) ${ }^{[2]}$ thought that a meme must have three characteristics to succeed: fidelity, prolificacy and longevity. According to Chesterman ${ }^{[3]}$, the vitality of translation memes is different. Some of them die because they can't be accepted universally. Some of them have strong vitality and can be spread. Based on the longevity characteristics of Memetics, this paper attempts to analyze the process of the reproduction and dissemination of brand names as memes in translation. Taking Luxury and Safeguard as examples, this research provides some references for the theoretical research and practical operation of brand translation.

\section{Literature Review}

Memetics, a term derived from sociobiology, is a new theory applied to explain the laws of cultural evolution based on Darwinian evolution. It was firstly seen in The Selfish Gene in 1976, written by zoologist R. Dawkins who is a NeoDarwinism advocator ${ }^{[4]}$. The core concept of Memetics is meme, which imitates gene, meaning "a unit for spreading culture". Imitation itself is a means of reproduction which is to copy the behavior of others. It definitely replicate something as imitation happens. Dawkins held the view that those languages, cultures, ideas and customs which can be reproduced and spread belong to the range of memes. Professor He Ziran et al translate meme into “模因” in Chinese $^{[2]}$. Language itself is a kind of meme, and meme is implied by language. Any words, phrases, sentences, paragraphs even the whole essay are able to become a meme, 
as long as they can be replicated and spread ${ }^{[1]}$.

Memetics is applied in many ways in daily life, and brand name translation can be one of the applications. According to Merriam-Webster Dictionary, brand name is an adopted name that is given by a manufacturer or merchant to an article or service to identify and distinguish it from other products, and can be used and protected as a trademark. A brand name can be spoken, such as words, letters, or numbers. Brand names have vital impacts on business activities. It directly affects the judgment of consumers about the values of commodities, and even determines their purchasing behavior, for the reason that a brand name has strong and favorable association with consumers. In other words, a brand name is able to appeal to consumers from many perspectives, making them to purchase the product. Furthermore, the name can make customers remember the brand. Therefore, the brand name is a type of meme due to its special trait and property-it can be reproduced and spread overseas. Thus, the translation of brand names plays a significant role in building business images and competing with other brands. A good translated brand name can both express the implication of goods and succeed in drawing the attention of consumers in target markets. Theoretically, the translation of brand names is to demonstrate the linguistic symbols of the source language via target language. Based on special communication methods, the translation of brand names can accomplish cross-cultural language interaction in the ways of imitation, reproduction and information transmission. In a consequence, to some extent, the translated brand names can be hailed as memes as well. Some researchers have found that the reproduction of memes of brand name in target markets have four phases: assimilation, retention, expression and transmission (Xiaohui, Dun., \& Xiaqing, Liu ) ${ }^{[5]}$. The socalled "assimilation" refers that memes can infect its host, be memorized and can be noticed, understood and accepted by receptors. "Retention" means to keep as long as the meme can in the host, and then acquires increasing opportunities to "be expressed" through voices, images or languages to other receptors so as to spread itself. Dawkins(1993) suggested that there are three characteristics of memes: fidelity, prolificacy and longevity ${ }^{[10]}$. The fidelity refers that the more loyal the meme is to the original meme in the process of reproduction, the higher the survival rate of the original meme will be; the prolificacy means that the faster the meme is reproduced, the wider the meme will be transmitted; and the longevity is that the longer the meme exists in brain, the easier it is to be remembered.

According to current situation of brand name translation on the ground of Memetics, some principles about brand name translation in the perspective of Memetics are summarized by existed studies ${ }^{[1]}$. First, the principle of readability and easily to remember, which is the basic element for translation of brand names. Those brief and catchy translated versions will appeal to hosts, also known as consumers, and gradually make them remember and reproduce in mind. All these contribute to further spread. Generally, the principle of readability and easily to remember is to be recognized at the fastest speed and evoke memory of the brand in the course of consumption. Taking HewlettPackare Co. as an example, it was translated into “休利特-帕 卡尔公司”, which was mouthful and not easy for consumers to memorize. However, the current translated version “惠普” is rather different: “Hew" is translated into “惠” and “Park" into “普”, which sounds brief as well as powerful. The second principle of translation of brand name, on the basis of Memetics, is the principle of cultural adaptation, which means translated versions need to comply with thinking patterns, values, ethics, personality traits as well as behavior of consumers in target markets, internalize these factors into the corresponding cultural psychology of target market, integrate into their social, political and economic fields, and eventually inherit in the form of meme or meme complex. Taking “红豆”(red bean in English) ${ }^{[7]}$, a fairly popular clothing brand in China, as an example, this study illustrates how this principle runs in translation. Red bean is a symbol of love in China, and there is a piece of poem named Love Seeds, written by Wang Wei, an ancient poet in China, in which the first line said "The red bean grows in southern lands. How many load the autumn trees". Grounded on the culture of "love", created by the poem, this company applied the translated name-"loved seed". More specifically, the "Red Bean Culture" refers to loyalty to love, missing for families, expectation to reunion, pursuit of wisdom, hope for a bright future as well as help for vulnerable groups, which fully fascinate overseas customers, and promote business performance of this company.

Principles of brand name translation can be hailed as the foundation, and the specific tactics will be considered as tools. In the course of translation of brand name, three strategies are commonly used. First, the transliteration can be seen in many 
cases, in which translated brand name is supposed to sound similar with that in source language. Pronunciation serves as the bond between source language brand name and translated language symbol. The target language symbols with effects of source language brand name can make the potential consumers associate with quality of the product and exoticism (Xiaqin, Zhou. ) ${ }^{[8]}$. With the development of translation theories and practices, this method is increasingly identified and used in brand name translation. More specifically, transliteration can be divided into three aspects: nonassociative translation, associative translation and ellipsis translation (Xiaqin, Zhou. ) ${ }^{[8]}$. With the progression of modernized urban life, aesthetic psychological as a kind of comprehensive culture, the aesthetic demand of people is increasingly on the rise. A proper and magnetic translated brand name in the use of associative translation, however, can get over the gaps of aesthetic standard of individuals and achieve the expected effects amid consumers. It has been universally recognized that the translation of Coca-Cola is unprecedented well-accepted in China than ever before. But its initial adopted translated name “蝌蚪啃蜡” and the odd brown color of the drink brought bleak performance, while after the application of the current name “可口可乐”:“Coca” is translated into “可口”, and “Cola” into “可乐”, this carbonated drink has appealed to various consumers, and has made a huge fortune. Therefore, “可口可乐” can be hailed as a successful meme. As of September 2019, Coca-Cola (KO. US) saw the revenue in the first half of the year in China exceeded $\$ 18$ billion, according to the report.

In the process of translation, translators intend to weigh options for words or

characters in hope of expressing the effects and functions of products vividly and accurately. However, it is better to apply literal translation in some cases. Literal translation is another method in brand name translation, which bases on the permission of target language, retains the content and format of source language, and directly introduce in the memes in the target language. Usually, the traditionally and widely accepted names in source language are literally translated, for instance, “恒源祥”, a traditional brand of garment in China), “全聚德(烤鸭)”, a food company based in Beijing, featured in roast duck and “同仁堂”, a Chinese medicine drug store established in Qing dynasty, are respectively translated into "Hengyuanxiang", "QuanJuDe" and "Tongrentang Chinese Medicine", which serve as unique cultural memes with Chinese features in international community. In every particular country, region or organization, there are timehonored traditional thoughts and ethics that have deep-rooted in people's mind can be considered as strong memes. For instance, there are some universally acknowledged traditional virtues in Chinese culture: benevolence, righteousness, manners, wisdom and credit. And both the oriental and western world attach great importance to freedom, equality, independence and other qualities of individuals, which serve as an essential tactic in choosing the proper and suitable characters or words as cultural memes during translating. New memes or weak memes can bind with those that possess wider range of acceptance so as to optimize the environment and conditions of transmission.

\section{Discussion}

With the global economy development, commodities can be sold around the world, so the importance of an accurate and appropriate brand name is ever increasing. Brand name is a special language phenomenon. As a special symbol to distinguish other goods or services, it carries the characteristics of the goods or services in the form of language and spreads among consumers. Its purpose is to make the goods sell well in the market. Each brand name carries a meme and represents the concepts as well as the cultural characteristics of manufacturers and enterprises. When goods enter the foreign market, through brand name translation, customers in the target country will know and understand the brand, become the host of memes of the brand name, and constantly copy and spread them. However, imitation in Memetics is not a single plagiarism, malicious infringement of intellectual property rights, but a shortcut to effective communication. In short, brand name translation is a process of cross-cultural reproduction and dissemination of brand memes (Xiaohui, Dun., \& Xiaqing, Liu ${ }^{\text {) }}{ }^{[4]}$.

As mentioned before, meme can be divided into strong meme and weak meme. Compared with weak meme or dead meme, those strong memes can be duplicated easily, circulated broadly and existed longer ${ }^{[9]}$. At this stage, translating brands name needs to avoid obscure words which means the brand name that has been recombination should not only conform to the language habits of the target language, but also reflect the concise and catchy features of the trademark. That's how a brand meme can catch customer's eyes and reach the purpose of infecting the receptor. The main 
idea of the second stage- retention is how long a meme can stay in the memory. Cause the memory is so picky that only a few Memes can survive. The third stage requires that the core of original brand meme need to stay the same with the new brand meme so as to fully embody memes that products or services carriers. At last stage, memes are enhancing their influence by expanding their propagation range with various carriers. The above four stages form a loop, which comes full circle. The choice runs through four stages. Based on that, brand memes can be divided into two forms: original brand memes and new brand memes. If the new brand meme survives through these four stages and will be accepted and widely spread by the consumers in the target country. We call it strong brand meme. However, in the process of transmission, if the new brand meme has not attracted the recognition, attention or been eliminated by the consumers. We call it a weak brand meme. Blackmore (1999) indicated that the meme which is highly authentic and long-term preservation is Effective Meme. There are a great number of memes that spread widely, in large part, because they are easy to remember.

Taking washing brands Luxury and Safeguard for example. Luxury is a world- famous washing brand. Since its creation, Luxury taking the "moist" "upmarket" as its core values and strive to give the brand "noble and luxurious" temperate. Safeguard entered China in 1999, taking "sterilization" and "antibacterial" as product features. In just a few years, with its high quality and accurate market positioning, it has achieved great success and become the leading brand of China's personal cleaning product market. Luxury entered the Chinese market as early as 1986 which was six years earlier than Safeguard. However, data indicated that in 2019, the soup that Safeguard produced had defeated Luxury to become the first in C-BPI(China Brand Power Index). Besides that, the brand association, brand loyalty and brand preference of Safeguard were all higher than Luxury. After the research, it can conclude that the reason why Safeguard is more acceptable than Luxury probably because it adapts the longevity of Memetics which means the brand name of Safeguard is easy to spell, read, understand and remember. Whatever it's the original brand memes or new brand memes.

\section{Conclusion}

Memetics provides a new strategy to research brand translation and explains the rationality of adding strong memes into brand translation from the perspective of cultural reproduction and transmission. Brand translation pays more attention to the actual effect in the target language and receivers. Translators should not only be proficient in both the original and target language, but also the cultures and knowledge of some special field. In brand translation, the translator can flexibly choose translation strategies to create a strong brand meme that conforms to the target language and culture habits, wins in fidelity, prolificacy and longevity, so as to infect and influence the target language readers, so as to promote the final purchase behavior.

\section{References}

[1] Shuping, Cao. (2011). A Research of Translation Strategies of Brand Name Based on Memetics. Journal of Changsha University (Social Science Edition), Vol.12, No.4, 175-176.

[2] Dawkins R. (1976). The Selfish Gene. New York :OUP.

[3] Chesterman A. (1996). Memes of Translation: The Spread of Ideas in Translation Theory. Amsterdam : John Benjaminis. [4] Xiaohui, Dun., \& Xiaqing, Liu. (2011). Study on Brand Name Translation under the Respective of Memetics. Overseas English, No.14, 167-168.

[5]Heylighe. (1992). Selfish Memes and the Evolution of Cooperation [J]. Journal of Ideas, No.4, 77-84.

[6] Jinyan, Yao. (2010). The Cultural Adaptation in Trademark Translation Under the Perspective of Cross-Cultural Exchanges. Business China, Vol.12, 387-388. [7] Yajun, Zhu. (2003). Trademark. Shanghai: Shanghai Foreign Language Education Press.

[8] Xiaqin, Zhou. (2010). The Analysis on the Application of Transliteration in English Trademark Translation[J]. Science \& Technology Information, No.34, 185.

[9] Cao Shuping, (2011.12). An analysis of Memetics of brand name, Seeker, 229-231.

[10] Liu Xiaomei, (2016). Advertisement Translation: A Memetic Perspective. Journal of Zhengzhou University of Aeronautics (Social Science Edition), Vol.35 No.1,135-138.

[11] Blackmore, S. The Meme Machine. Oxford: Oxford University Press.1999:66. 